\title{
PENGARUH KUALITAS LAYANAN TERHADAP KEPUASAN PASIEN PADA PUSKESMAS KAMONJI DI KOTA PALU
}

\author{
AGFINIA HARDIYANTI PUTRI \\ ELIMAWATY ROMBE \\ CHALIL \\ Program Studi S1 Manajemen, Fakultas Ekonomi, Universitas Tadulako \\ Email: agfinia@gmail.com
}

\begin{abstract}
The purpose of this study is to determine the effect of service quality consisting of physical evidence, reliability, responsiveness, assurance and empathy on patient satisfaction at the Puskesmas Kamonji in Palu. The sample used is 90 respondents, with sampling technique used is purposive sampling. Data analysis method used in this research is Multiple Linear Regression. The results showed that the service quality variable consisting of physical evidence, reliability, responsiveness, assurance and empathy simultaneously had a significant effect on patient satisfaction at Kamonji Puskesmas in Palu. While partially physical proof, kahandalan, responsiveness, assurance and empathy also have a significant effect on patient satisfaction at Puskesmas Kamonji in Palu.
\end{abstract}

Keywords: Quality of Service, Patient Satisfaction

\begin{abstract}
Abstrak
Tujuan dari penelitian ini yaitu untuk mengetahui pengaruh kualitas layanan yang terdiri bukti fisik, kahandalan, daya tanggap, jaminan dan empati terhadap kepuasan pasien pada Puskesmas Kamonji di Palu. Sampel yang digunakan penelitian ini yaitu sebanyak 90 responden, dengan teknik penarikan sampel yang digunakan adalah purposive sampling. Metode analisis data yang digunakan dalam penelitian ini adalah Regresi Linear Berganda. Hasil penelitian menunjukkan bahwa variabel kualitas layanan yang terdiri bukti fisik, kahandalan, daya tanggap, jaminan dan empati secara serempak berpengaruh signifikan terhadap kepuasan pasien pada Puskesmas Kamonji di Palu, sedangkan secara parsial bukti fisik, kahandalan, daya tanggap, jaminan dan empati juga berpengaruh signifikan terhadap kepuasan pasien pada Puskesmas Kamonji di Palu.
\end{abstract}

Kata Kunci: Kualitas Layanan, Kepuasan Pasien

\section{PENDAHULUAN}

Mewujudkan keadaan sehat merupakan kehendak semua pihak, hal ini tidak hanya oleh individu, tetapi juga oleh keluarga, kelompok dan bahkan masyarakat. Penyelenggaraan pelayanan kesehatan untuk masyarakat di tingkat dasar di Indonesia adalah melalui Pusat Kesehatan Masyarakat (Puskesmas) yang merupakan unit organisasi fungsional Dinas Kesehatan kabupaten maupun kota diberi tanggung jawab sebagai pengelola kesehatan bagi masyarakat tiap wilayah kecamatan dari kota yang bersangkutan. Kesehatan adalah aset sekaligus sumber daya untuk menciptakan stabilitas ekonomi dan sosial. Kesehatan yang berkualitas mampu meningkatkan usia harapan hidup, menurunkan angka kematian, serta meningkatkan produktivitas. Sehingga pada gilirannya, peningkatan produktivitas mampu diberdayakan untuk mengakselerasi roda pembangunan menuju kesejahteraan.

Kualitas layanan tentu saja tidak hanya sebatas senyum ramah dari pegawai puskesmas saja, melainkan lebih dari itu. Lupiyoadi dan Hamdani (2013:216) terdapat lima dimensi utama yang relevan untuk menjelaskan kualitas pelayanan yang dikenal dengan service quality (servqual) yaitu, bukti fisik, kehandalan, daya tanggap, jaminan, dan empati. Berdasarkan uraian latar belakang tersebut, penulis melakukan penelitian dengan judul yaitu: "Pengaruh Kualitas Layanan Terhadap Kepuasan Pasien Pada Puskesmas Kamonji Di Palu”. 
Putri, A.H.

\section{KAJIAN LITERATUR DAN PENGEMBANGAN HIPOTESIS}

\section{Kualitas Layanan}

Kualitas layanan menjadi suatu keharusan yang harus dilakukan perusahaan agar dapat mampu bertahan dan tetap mendapat kepercayaan pelanggan. Kualitas layanan pada umumnya dikaitkan dengan suatu tingkat keberhasilan atau suatu yang excellen, yang merupakan derajat kesempurnaan hasil yang melampaui tingkat rata-rata. Kotler dan Keller (2009:143) mengemukakan bahwa kualitas (quality) adalah totalitas fitur dan karakteristik produk atau jasa yang bergantung pada kemampuannya untuk memuaskan kebutuhan yang dinyatakan atau tersirat. Tjiptono (2011:59) berpendapat kualitas pelayanan adalah tingkat keunggulan yang diharapkan dan pengendaliannya atas tingkat keunggulan tersebut untuk memenuhi keinginan pelanggan.

\section{Dimensi Kualitas Layanan}

Kualitas adalah pada dasarnya bersifat relatif yaitu tergantung dari perspektif yang digunakan untuk menetukan ciri-ciri, namun secara umum pengertian kualitas dapat didefenisikan sebagai fiturfitur yang memiliki kesesuaian antara apa yang dirasakan konsumen dengan apa yang diharapkannya. Sinambela (2011:7) mengelompokkan kualitas pelayanan publi kedalam lima dimensi sebagai berikut:

1. Reliabilitas (reliability) yang ditandai pemberian pelayanan yang tepat dan benar.

2. Ketampakan fisik (tangibles) yang ditandai dengan penyediaan yang memadai sumber daya manusia dan sumber daya lainnya.

3. Responsivitas (rensponsiveness) yang ditandai dengan keinginan melayani konsumen dengan cepat.

4. Kepastian (assurance) yang ditandai dengan tingkat perhatian terhadap etika moral dalam memberikan pelayanan.

5. Empati (empathy) yang ditandai tingkat kemauan untuk mengetahui keinginan dan kebutuhan konsumen.

\section{Kepuasan Konsumen}

Kepuasan konsumen merupakan perbedaan antara yang diharapkan pelanggan (nilai harapan) dengan situasi yang diberikan perusahaan di dalam usaha memenuhi harapan pelanggan. Laksana (2008:10) mengartikan bahwa kepuasan pelanggan dapat didefinisikan secara sederhana sebagai suatu keadaan dimana kebutuhan, keinginan dan harapan pelanggan dapat terpenuhi melalui produk yang dikonsumsi. Lupiyoadi dan Hamdani (2013:192) mengartikan bahwa kepuasan merupakan tingkat perasaan dimana seseorang menyatakan hasil perbandingan atas kinerja produk (jasa) yang diterima dan yang diharapkan.

\section{Kerangka Pemikiran}

Kepuasan pasien merupakan perbandingan antara kenyataan yang dirasakan konsumen dengan apa yang diharapkan pelanggan. Apabila yang dirasakan pelanggan melebihi dari apa yang diharapkan, hal tersebut berarti pelanggan telah terpenuhi kepuasannya. Jika pelanggan telah merasa puas, biasanya akan melakukan kegiatan pembelian ulang atau merekomendasikan kepada pihak lain terhadap produk atau jasa tersebut dikemudian hari serta pelanggan akan lebih puas terhadap perusahaan tersebut. Sebagaimana Puskesmas Kamonji, lebih kompetitif memberikan pelayanan kepada masyarakat harus senantiasa berupaya memberikan pelayanan yang baik dan konsisten terhadap kualitas pelayanan yang diberikan agar kepuasan konsumen tercapai. Berdasarkan pemaparan di atas, maka dapat digambarkan kerangka pemikiran mengenai Pengaruh Kualitas Layanan Terhadap Kepuasan Pasien Pada Puskesmas Kamonji di Palu. Untuk lebih jelasnya kerangka pemikiran tersebut, dapat dilihat pada Gambar 1 berikut ini: 


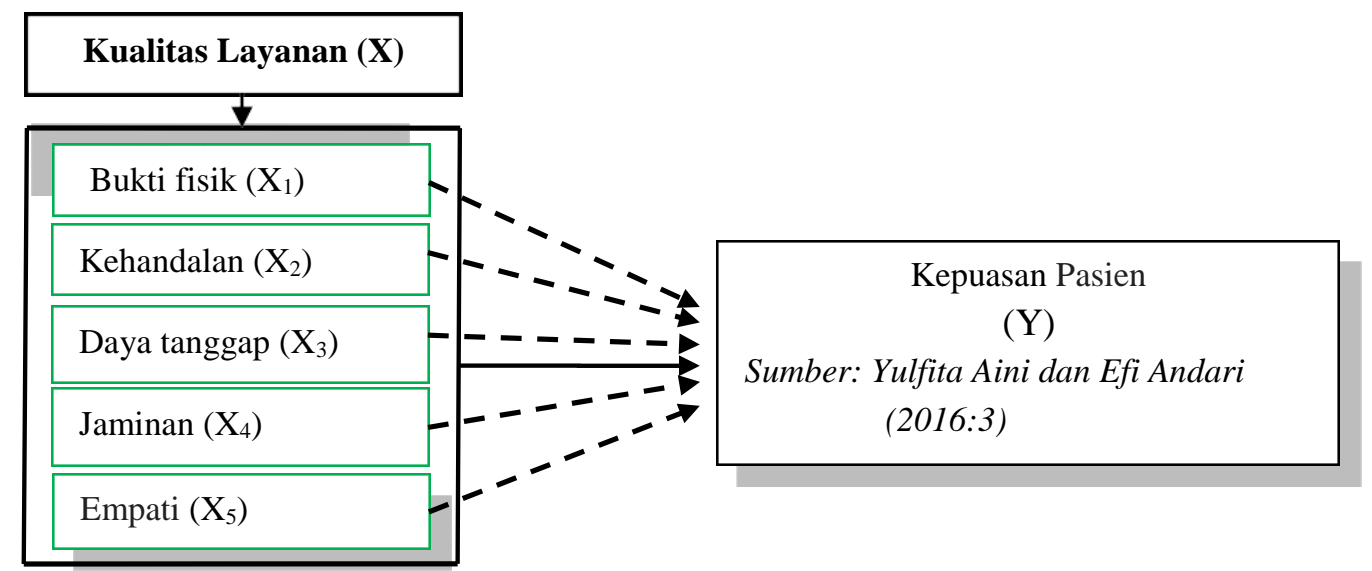

Sumber: Sinambela (2011:7)

\section{Gambar 1 \\ Kerangka Pemikiran}

\section{Hipotesis}

Berdasarkan latar belakang serta rumusan mahasalah yang telah dikemukakan sebelumnya, maka dapat diajukan hipotesis, yaitu sebagai berikut:

1. Kualitas layanan yang terdiri bukti fisik, kahandalan, daya tanggap, jaminan dan empati secara serempak berpengaruh signifikan terhadap kepuasan pasien pada Puskesmas Kamonji di Palu.

2. Bukti fisik berpengaruh signifikan terhadap kepuasan pasien pada Puskesmas Kamonji di Palu.

3. Kahandalan berpengaruh signifikan terhadap kepuasan pasien pada Puskesmas Kamonji di Palu.

4. Daya tanggap berpengaruh signifikan terhadap kepuasan pasien pada Puskesmas Kamonji di Palu.

5. Jaminan berpengaruh signifikan terhadap kepuasan pasien pada Puskesmas Kamonji di Palu.

6. Empati berpengaruh signifikan terhadap kepuasan pasien pada Puskesmas Kamonji di Palu.

\section{METODE PENELITIAN}

Jenis penelitian yang digunakan yaitu bersifat deskriptif kausal. Umar (2005:21) menyatakan bahwa deskriptif bertujuan untuk menjawab pertanyaan menyangkut sesuatu pada waktu berlangsungnya riset. Penelitian kausal adalah penelitian untuk menguji hubungan kausalitas antara variabel yang dihipotesakan. Teknik pengumpulan data dilakukan dengan cara observasi, interview, kuisioner, dan dokumentasi. Populasi dalam penelitian ini adalah seluruh masyarakat yang berobat pada Puskesmas Kamonji. Teknik penarikan sampel yang digunakan dalam penelitian ini, yaitu purposive sampling. Sugiyono (2010:130) menyatakan bahwa bila dalam penelitian akan melakukan analisis dengan multivariat (korelasi atau regresi ganda misalnya), maka jumlah anggota sampel minimal 10 kali dari jumlah variabel yang diteliti. Berdasarkan pendapat tersebut, maka dapat ditentukan besarnya jumlah sampel yang diteliti, yaitu 15 × $6=90$ responden.

\section{Metode Analisis}

Menjawab permasalahan serta hipotesis yang diajukan digunakan alat analisis statistik, yaitu Regresi Berganda (Multiple Linear Regression). Adapun penggunaan regresi berganda terkait dengan permasalahan dan hipotesis yang diajukan dalam penelitian pengaruh variabel independen (X) terhadap dependen (Y) melalui melalui pengolahan SPSS 16. 


\section{HASIL DAN PEMBAHASAN}

Berikut hasil mengenai pengaruh variabel bebas baik secara serempak maupun parsial yang diolah SPSS 16.0 dengan analisis regresi linier berganda seperti pada Tabel 1 berikut ini:

Tabel 1

Rekapitulasi Hasil Analisis Regresi Linear Berganda

\begin{tabular}{|c|c|c|c|}
\hline \multicolumn{3}{|c|}{ Dependen Variabel Y = Kepuasan Pasien } & \multirow{3}{*}{ Sig. } \\
\hline \multirow[b]{2}{*}{ Variabel Independen } & \multicolumn{2}{|c|}{ Unstandardized Coefficients } & \\
\hline & B & Standar Error & \\
\hline (Constant) & .303 & .394 & .444 \\
\hline X1_Bukti_Fisik & .199 & .046 & .000 \\
\hline X2_Kehandalan & .259 & .066 & .000 \\
\hline X3_Daya_Tanggap & .114 & .051 & .028 \\
\hline X4_Jaminan & .119 & .048 & .015 \\
\hline X5_Empati & .255 & .059 & .000 \\
\hline $\begin{array}{l}\text { Multiple } \mathrm{R}=0.759^{\mathrm{a}} \\
=0.000\end{array}$ & R Squar & $=0.577$ & ig.F \\
\hline
\end{tabular}

Berdasarkan bentuk penjabaran di atas, menunjukan bahwa variabel independen yang dianalisis yaitu variabel $\left(\mathrm{X}_{1}, \mathrm{X}_{2}, \mathrm{X}_{3}, \mathrm{X}_{4}\right.$, dan $\left.\mathrm{X}_{5}\right)$ memberi pengaruh positif terhadap variabel dependen $(\mathrm{Y})$, yaitu kepuasan pasien pada Puskesmas Kamonji di Palu. Untuk lebih rincinya penjelasan bentuk persamaan tersebut, dapat berikut ini:

1. Berdasarkan bentuk persamaan di atas, menunjukkan bahwa koefisien variabel bukti fisik $\left(\mathrm{X}_{1}\right)$ sebesar 0.303. Hal ini bermakna bahwa semakin meningkat bukti fisik, maka kepuasan pasien juga meningkat demikian pula sebaliknya.

2. Berdasarkan bentuk persamaan di atas, menunjukkan bahwa koefisien variabel kehandalan $\left(\mathrm{X}_{2}\right)$ sebesar 0.199. Hal ini bermakna bahwa semakin meningkat kehandalan, maka kepuasan pasien juga meningkat demikian pula sebaliknya.

3. Berdasarkan bentuk persamaan di atas, menunjukkan bahwa koefisien variabel daya tanggap $\left(\mathrm{X}_{3}\right)$ sebesar 0.114 . Hal ini bermakna bahwa semakin meningkat daya tanggap, maka kepuasan pasien juga meningkat demikian pula sebaliknya.

4. Berdasarkan bentuk persamaan di atas, menunjukkan bahwa koefisien variabel jaminan $\left(\mathrm{X}_{4}\right)$ sebesar 0.119. Hal ini bermakna bahwa semakin meningkat jaminan, maka kepuasan pasien juga meningkat demikian pula sebaliknya.

5. Berdasarkan bentuk persamaan di atas, menunjukkan bahwa koefisien variabel empati $\left(\mathrm{X}_{5}\right)$ sebesar 0.255. Hal ini bermakna bahwa semakin meningkat empati, maka kepuasan pasien juga meningkat demikian pula sebaliknya.

Berdasarkan tabel rekapitulasi regresi linear menunjukkan bahwa secara serempak bukti fisik, kehandalan, daya tanggap, jaminan, dan empati berpengaruh signifikan terhadap kepuasan pasien pada Puskesmas Kamonji di Palu. Bukti fisik, kehandalan, daya tanggap, jaminan, dan empati secara parsial juga berpengaruh signifikan terhadap kepuasan pasien pada Puskesmas Kamonji di Palu.

\section{Pembahasan}

1. Bukti Fisik $\left(\mathrm{X}_{1}\right)$

Berdasarkan hasil pengujian serta analisis yang telah dilakukan pada penelitian ini membuktikan bahwa variabel bukti fisik berpengaruh signifikan terhadap kepuasan pasien pada Puskesmas Kamonji di Palu. Pelayanan Puskesmas Kamonji kepada masyarakat yang ingin berobat telah disediakan sarana dan prasarana yang menunjang, seperti kondisi gedung yang 
nyaman. Dikarenakan baik dari luar gedung hingga didalam ruangan semuanya terlihat bersih. Bagi setiap pasien yang datang telah disediakan ruang tunggu yang dilengkapi dengan kursikursi tempat duduk. Selain itu juga Puskesmas Kamonji dilengkapi dengan interior ruangan yang baik, seperti poster maupun gambar-gambar mengenai hidup sehat yang ditempelkan di dinding Puskesmas Kamonji, sedangkan untuk kenyaman pasien apabila datang pada Puskesmas Kamonji menggunakan kendaraan pribadi telah disediakan tempat parkir, sehingga saat memarkirkan kendaraannya yang dibawanya dapat merasa aman. Walaupun ada beberapa pasien yang memarkirkan kendaraannya dipinggir jalan tetapi telah dijaga oleh tukang parkir, sehingga tetap merasa aman.

2. Kehandalan $\left(\mathrm{X}_{2}\right)$

Berdasarkan hasil pengujian serta analisis yang telah dilakukan pada penelitian ini membuktikan bahwa variabel kehandalan berpengaruh signifikan terhadap kepuasan pasien pada Puskesmas Kamonji di Palu. Ditunjukkan dengan indikator prosedur penerimaan pasien yang cepat saat datang untuk berobat di Puskesmas Kamonji. Saat pasien datang hanya harus melakukan pendaftaran terlebih dahulu kemudian menunggu antrian sampai dengan namanya atau nomor urutannya dipanggil. Sedangkan pelayanan pemeriksaan yang dilakukan oleh dokter Puskesmas Kamonji juga tergolong cepat, saat pasien yang butuh pertolongan lebih dini dokter langsung mengambil tindakan dengan melakukan perawatan secara cepat terhadap penyakit yang diderita oleh pasien tersebut. Selain itu demi mengantisipasi setiap pasien yang ingin berobat diwaktu-waktu tertentu Puskesmas Kamonji juga menjalankan jadwal pelayanan dengan tepat, seperti saat ini Puskesmas Kamonji buka sampai dengan sore hari.

3. Daya Tanggap $\left(\mathrm{X}_{3}\right)$

Berdasarkan hasil pengujian serta analisis yang telah dilakukan pada penelitian ini membuktikan bahwa variabel daya tanggap berpengaruh signifikan terhadap kepuasan pasien pada Puskesmas Kamonji. Upaya merespon masyarakat pagawai Puskesmas Kamonji harus memberikan pelayanan dengan cepat. Sehingga setiap pasien yang datang untuk berobat merasa dilayani dengan cepat, permintaannyapun ditanggapi dengan cepat, serta setiap kali pasien mengalami kesulitan dapat dibantu dengan cepat. Sikap seperti ini, wajib dilakukan oleh setiap pegawai Puskesmas Kamonji kepada setiap pasien yang datang serta hendak berobat. Sehingga masyarakat maupun pasien kedepannya tidak lagi kesulitan apabila datang kembali untuk berobat pada Puskesmas Kamonji Palu Barat. Pelayanan yang diberikan oleh pegawai Puskesmas Kamonji kepada pasien dapat sesuai dengan keinginan maupun yang diharapkan.

4. Jaminan $\left(\mathrm{X}_{4}\right)$

Berdasarkan hasil pengujian serta analisis yang telah dilakukan pada penelitian ini membuktikan bahwa variabel jaminan berpengaruh signifikan terhadap kepuasan pasien pada Puskesmas Kamonji di Palu. Sehingga dengan ini diharapakan kepada setiap pegawai Puskesmas Kamonji, baik dari petugas administrasi, perawat, maupun dokter agar dalam melayani pasien selalu besikap ramah. Sehingga nantinya setiap pasien yang datang pada Puskesmas Kamonji dapat merasa nyaman. Dikarenakan mereka merasa dihargai atau diberikan jaminan bahwa apabila datang berobat akan diperlakukan dengan sebaik mungkin. Jaminan merupakan kepastian mengenai kemampuan pegawai Puskesmas Kamonji dalam memberikan pelayanan yang ramah kepada setiap pasien yang datang hendak berobat pada puskesmas tersebut tanpa adanya pembedaan status golongan.

5. Empati $\left(\mathrm{X}_{5}\right)$

Berdasarkan hasil pengujian serta analisis yang telah dilakukan pada penelitian ini membuktikan bahwa variabel empati berpengaruh signifikan terhadap kepuasan pasien pada Puskesmas Kamonji di Palu. Sehingga dengan ini diharapkan agar Dokter Puskesmas Kamonji 
Putri, A.H.

selalu memahami akan kebutuhan pasien. Karena dengan memahami kebutuhan pasien dengan baik seperti pemberian pelayanan yang baik dapat membuat pasien merasa nyaman yang pada akhirnya akan berpengaruh juga pada tingkat kesehatannya. Puskesmas Kamonji dalam memberikan pelayanan kepada pasiennya juga memberikan fasilitas yang sesuai dengan kebutuhan pasien, sehingga saat dilakukan proses pemeriksaan kepada pasien dapat berjalan secara maksimal. Selain itu juga beberapa perawat atau bidan yang ada pada Puskesmas Kamonji cukup baik karena telah memahami kebutuhan pasien.

\section{KESIMPULAN DAN SARAN}

\section{Kesimpulan}

1. Kualitas layanan yang terdiri bukti fisik, kahandalan, daya tanggap, jaminan dan empati secara serempak berpengaruh signifikan terhadap kepuasan pasien pada Puskesmas Kamonji di Palu.

2. Bukti fisik berpengaruh signifikan terhadap kepuasan pasien pada Puskesmas Kamonji di Palu.

3. Kahandalan berpengaruh signifikan terhadap kepuasan pasien pada Puskesmas Kamonji di Palu.

4. Daya tanggap berpengaruh signifikan terhadap kepuasan pasien pada Puskesmas Kamonji di Palu.

5. Jaminan berpengaruh signifikan terhadap kepuasan pasien pada Puskesmas Kamonji di Palu.

6. Empati berpengaruh signifikan terhadap kepuasan pasien pada Puskesmas Kamonji di Palu.

\section{Saran}

1. Kepada Puskesmas Kamonji, dapat lebih meningkatkan kualitas pelayanan yang tediri dari bukti fisik, kehandalan, daya tanggap, jaminan, dan empati yang telah terbukti berpengaruh signifikan terhadap kepuasan pasien pada Puskesmas Kamonji di Palu.

2. Kepada Puskesmas Kamonji dapat memperhatikan beberapa indikator berikut ini, dikarenakan memiliki nilai mean terendah dari indikator lainnya. Adapun indikator tersebut seperti kondisi gedung luas, prosedur penerimaan pasien yang cepat, jadwal pelayanan dijalankan dengan tepat waktu, memberikan pelayanan dengan cepat, petugas ramah dalam melayani pasien dan perawat/bidan memahami akan kebutuhan pasien, sehingga kedepannya setiap kebutuhan pasien dapat terpenuhi dengan baik.

\section{REFERENSI}

Kepmenkes Repulik Indonesia No.128/Menkes/SK/II/2004. Tentang Kebijakan Dasar Puskesmas.

Kotler, Philip dan Keller. (2009). Manajemen Pemasaran. Terjemahan Benyamin Molan, Edisi Ketiga belas, Jilid I, Ciracas, Jakarta: Erlangga.

Laksana Fajar. (2008). Manajemen Pemasaran. Yogyakarta: Graha Ilmu.

Lupiyoadi Rambat dan Hamdani. 2013. Manajemen Pemasaran Jasa. Jakarta: Salemba Empat.

Sinambela Lijan Poltak, dkk. 2011. Reformasi Pelayanan Publik. Jakarta: Bumi Aksara.

Sugiyono, 2010. Metode Penelitian Bisnis. Bandung: Penerbit Alfabeta.

Tjiptono Fandy. 2011. Pemasaran Jasa. Malang: Bayumedia.

Umar Husein. 2005. Metode Penelitian Skripsi dan Tesis Bisnis. Edisi Baru. Jakarta: RajaGrafindo Persada. 